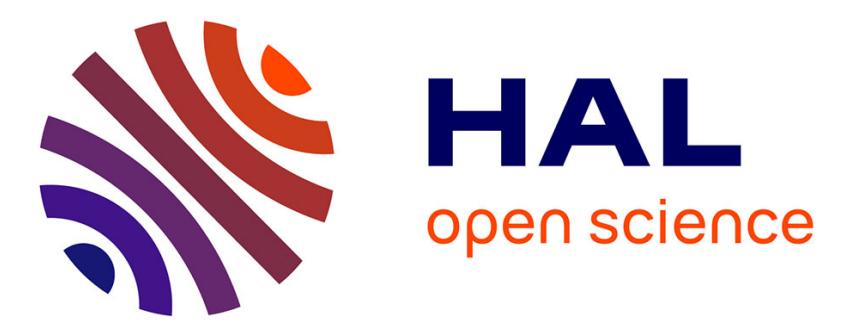

\title{
Catecholamine, blood lactate and ventilatory responses to multi-cycle-run blocks
}

Olivier Hue, Daniel Le Gallais, Alain Boussana, Olivier Galy, Karim Chamari, Betty Mercier, Christian Prefaut

\section{- To cite this version:}

Olivier Hue, Daniel Le Gallais, Alain Boussana, Olivier Galy, Karim Chamari, et al.. Catecholamine, blood lactate and ventilatory responses to multi-cycle-run blocks. Medicine and Science in Sports and Exercise, 2000, 32 (9), pp.1582-1586. 10.1097/00005768-200009000-00009 . hal-00720475

\section{HAL Id: hal-00720475 https://hal.univ-antilles.fr/hal-00720475}

Submitted on 24 Jul 2012

HAL is a multi-disciplinary open access archive for the deposit and dissemination of scientific research documents, whether they are published or not. The documents may come from teaching and research institutions in France or abroad, or from public or private research centers.
L'archive ouverte pluridisciplinaire HAL, est destinée au dépôt et à la diffusion de documents scientifiques de niveau recherche, publiés ou non, émanant des établissements d'enseignement et de recherche français ou étrangers, des laboratoires publics ou privés. 


\title{
Catecholamine, blood lactate and ventilatory responses to multi-cycle- run blocks
}

\author{
OLIVIER HUE, D. LE GALLAIS, A. BOUSSANA, O. GALY, K. CHAMARI, B. MERCIER, and C. PREFAUT \\ Laboratoire Sport, Performance, Santé, UPRES-EA, UFR-STAPS, 34090 Montpellier, FRANCE; and Laboratoire de \\ Physiologie des Interactions, Service Central de Physiologie Clinique, Unité d'Exploration Respiratoire, Centre \\ Hospitalier Universitaire Arnaud de Villeneuve, 34295 Montpellier Cedex 5, FRANCE
}

\begin{abstract}
HUE, O., D. LE Gallais, A. BousSANA, O. GALY, K. CHAMARI, B. MERCIER, and C. PREFAUT. Catecholamine, blood lactate and ventilatory responses to multi-cycle-run blocks. Med. Sci. Sports Exerc., Vol. 32, No. 9, pp. 1582-1586, 2000. Purpose and Methods: This study was designed to determine whether the physiological responses elicited during the run part of repeated bouts of cycle-run exercise are similar to those required during the run segment of a cycle-run succession. Thirteen male triathletes underwent four successive laboratory trials: 1) an incremental treadmill test, 2) an incremental cycle test, 3) $30 \mathrm{~min}$ of cycling followed by $20 \mathrm{~min}$ of running (C-R), and 4) five repeated bouts of 6 min of cycling and $4 \mathrm{~min}$ of running (X-CR). During the C-R and X-CR trials, venous blood samples were obtained to measure lactate, epinephrine and norepinephrine concentrations. During all trials, ventilatory data were collected every min using an automated breath-by-breath system. Results: The results showed that 1) the cardiorespiratory responses observed during running were similar in the X-CR and C-R trials, 2) the lactate concentration was similar in both trials, 3) the epinephrine concentration was greater $\left(277.9 \pm 11.9\right.$ vs $\left.169.8 \pm 86.7 \mathrm{pg} \cdot \mathrm{mL}^{-1}, P<0.025\right)$ in X-CR than in C-R, and 4) the norepinephrine concentration was similar in both trials, except at the first cycle-run succession (T1) of X-CR. Conclusion: We concluded that 1) multi-block training is a good method to stimulate the specific adaptations required for the cycle-run succession, and particularly for the cycle-run transition, and 2) multi-block training seems to induce a greater catecholaminergic response, which may be due to a combination of an inherent effect of this type of training and the triathletes' relative lack of experience with it. In any case, the efficacy of the multi-block model needs to be more thoroughly evaluated over the course of a longer-term training program. Key Words: TRIATHLON, CYCLE-RUN SUCCESSION, MULTI-BLOCK TRAINING, LACTATE
\end{abstract}

$\mathrm{T}$ Triathlon training consists mainly of high-volume and interval training in the three sports independently (22), although Kreider et al. (18) suggested that triathlon performance elicits physiological adjustments not experienced when performing the events independently. In the Olympic Distance Triathlon ( $1.5 \mathrm{~km}$ swim, $40 \mathrm{~km}$ cycle and 10 $\mathrm{km}$ run), run performance has become particularly crucial to the final result because of a new rule that permits drafting; i.e., cycling directly behind another cyclist or in group, during the cycling segment. Recently, Hue et al. (15) reported that the run subsequent to cycling is characterized by a greater ventilatory response when compared with a run performed independently. These authors noted that the first min of the subsequent run, termed the "transition", elicited a particularly high ventilatory response that is specific to the successive cycle-run (16), and which may limit the triathlon performance.

Repeated bouts of cycle-run exercise, i.e., "multi-block training", have been suggested as a means to enhance the

0195-9131/00/3209-1582/0

MEDICINE \& SCIENCE IN SPORTS \& EXERCISE

Copyright $\odot 2000$ by the American College of Sports Medicine

Submitted for publication April 1999.

Accepted for publication December 1999. specific physiological adaptations elicited during both the cycle-run transition and the entire subsequent run $(6,15,16,18)$, but this has never been investigated. The aim of the present study was to investigate whether multi-block training enhances the physiological adaptations requires during the cycle-run succession in triathletes. The study wa therefore designed to compare the physiological response elicited in triathletes during repeated bouts of cycle-run exercise with those elicited during a single successive cyclerun. We hypothesised that a similar ventilatory response during the run segment of multi-block training and the transition period of a simulated cycle-run sequence of the triathlon would constitute evidence that multi-block training is a good training model for these athletes.

\section{MATERIALS AND METHODS}

Subjects. Thirteen male competitive triathletes participated in this study. All were students at the School of Physical Education at the University of Montpellier, France. and they were members of the university athletic team. which has been French national champion in the triathlon for four consecutive yr. Average competitive experience ir the triathlon was $6.0 \pm 2.3 \mathrm{yr}$, and subjects were in th: 
TABLE 1. Anthropometric data, training reginows values are means \pm SEM.

\begin{tabular}{|c|c|c|c|c|c|c|c|c|c|}
\hline \multirow[b]{2}{*}{ Age (yr) } & \multirow[b]{2}{*}{ Height (cm) } & \multirow{2}{*}{$\begin{array}{c}\text { Weight } \\
(\mathrm{kg})\end{array}$} & \multicolumn{2}{|c|}{$\dot{v} O_{2 \max }\left(\mathrm{mL} \cdot \mathrm{kg}^{-1} \cdot \min { }^{-1}\right)$} & \multicolumn{2}{|c|}{$\mathrm{Th}_{\text {vemt }} \% \dot{\mathrm{V}} \mathrm{O}_{2 \max }$} & \multicolumn{3}{|c|}{ Mean Training Distances $\left(\mathrm{km} \cdot \mathrm{wk}^{-1}\right)$} \\
\hline & & & $\mathrm{CE}$ & TR & CE & TR & Swim & Bike & Run \\
\hline $23.1 \pm 1.2$ & $180.6 \pm 2.0$ & $71.7 \pm 1.8$ & $67.2 \pm 1.6$ & $68.8 \pm 1.8$ & $65.9 \pm 2.8$ & $68.0 \pm 1.9$ & $17.3 \pm 0.7$ & $288.8 \pm 27.9$ & $47.7 \pm 4.3$ \\
\hline
\end{tabular}

competitive period (from June to August) at the time of the study. Anthropometric data. physiological data, and training regimens are reported in Table 1 . All subjects were informed of the purpose of the study and gave written consent :n accordance with the regional Ethics Committee before participating.

Testing protocol. Each subject was tested in a four-trial protocol that took place over four consecutive weeks. The tests were conducted at the same time of day and during the same day of the week to minimize the effects of the personal training on results. The subjects were asked to maintain their training schedule for the duration of the study but were not allowed to compete in a triathlon during the testing period. All subjects were familiarized with treadmill running and the use of the cycle ergometer before testing. The subjects were asked to refrain from training on experimental days. Trial 1 consisted of an incremental treadmill test; trial 2, an incremental cycle test; trial 3, $30 \mathrm{~min}$ of cycling followed by $20 \mathrm{~min}$ of running (C-R); and trial 4, five repeated bouts of $6 \mathrm{~min}$ of cycling and $4 \mathrm{~min}$ of running (X-CR) at exactly the same cycling and running speed evolutions as in C-R. The cycling and running $\mathrm{VO}_{2 \max }$ and ventilatory threshold $\left(\mathrm{Th}_{\text {vent }}\right)$ values measured in trials 1 and 2 were used to monitor the cycling and running intensities during the $\mathrm{C}-\mathrm{R}$ and $\mathrm{X}-\mathrm{CR}$ trials. The incremental treadmill (Gymroll 1800, Gymroll, Roche La Molière, France) test began at $5 \mathrm{~km} \cdot \mathrm{h}^{-1}$ for one min at $0 \%$ grade. The speed was then increased by $1 \mathrm{~km} . \mathrm{h}^{-1}$ every min up to a maximum speed of $18 \mathrm{~km} \cdot \mathrm{h}^{-1}$. The speed was then held constant and the grade was increased by $1 \%$ every min up to exhaustion. The incremental cycle test was performed on an electromagnetic cycle ergometer (Monark 864, Monark-Crescent AB, Varburg, Sweden). After a 3-min warm-up at $30 \mathrm{~W}$, the power was then increased by $30 \mathrm{~W}$ every min up to exhaustion. In trial 3 , the cycling was performed by the triathletes using their own cycle set on a home trainer (Cycletrack, Tacx, Aardenburg, Holland). The speed and gear ratio was calculated to be close to the athlete's performance level in the triathlon and above the $\mathrm{Th}_{\mathrm{vent}}$ calculated in trial 2 . At the end of the $30 \mathrm{~min}$ of cycling, the subjects had one min to change their shoes and get on the readmill. This time corresponded approximately to the cycleiun change time in an official triathlon. The athletes began the 20-min run at a speed calculated to be close to their performance level in a classic triathlon and above the $\mathrm{Th}_{\mathrm{vent}}$ calculated in trial 1 . This run speed was reached in less than $1 \mathrm{~min}$. In trial 4, the triathletes cycled for $6 \mathrm{~min}$ at the exact same cycling speed as in trial 3; they then had $1 \mathrm{~min}$ to change their shoes and get on the treadmill to run for $4 \mathrm{~min}$ at the exact same running speed as in trial 3 . They then had $1 \mathrm{~min}$ to get on the ycle again. The subjects repeated this 6 plus 4 min cycle-run bout a total of 5 times.

Gas exchange measurements. Cardiopulmonary data were continuously monitored and measured every min using a mass spectrometer breath-by-breath automated system (MGA-1100, Marquette. NY, U.S.): $\min$ ventilation $\left(\dot{\mathrm{V}}_{\mathrm{E}}\right)$, oxygen uptake $\left(\dot{\mathrm{VO}}_{2}\right)$, carbon dioxide production $\left(\dot{\mathrm{V} C \mathrm{O}_{2}}\right)$, respiratory equivalents for $\mathrm{O}_{2}\left(\dot{\mathrm{V}}_{\mathrm{E}} / \dot{\mathrm{VO}}_{2}\right)$ and $\mathrm{CO}_{2}$ $\left(\dot{\mathrm{V}}_{\mathrm{E}} / \dot{\mathrm{V}}_{2}\right)$, respiratory exchange ratio $(\mathrm{R})$, breathing frequency $(\mathrm{f})$, and tidal volume $\left(\mathrm{V}_{\mathrm{T}}\right)$. Heart rate $(\mathrm{HR})$ was measured using a telemetry system (Polar Racer, Polar Electro, Kempele, Finland). The ventilatory threshold $\left(\mathrm{Th}_{\mathrm{vent}}\right)$ was automatically determined using the V-slope method of Beaver et al. (2). This method involves the analysis of $\mathrm{VCO}_{2}$ as a function of $\mathrm{VO}_{2}$ and assumes that the $\mathrm{Th}_{\text {vent }}$ corresponds to the breakpoint in the $\mathrm{VCO}_{2}-\mathrm{VO}_{2}$ relationship.

Blood sampling. A venous catheter was inserted in a superficial forearm vein before the C-R and X-CR trials to allow sampling for measurement of lactate, epinephrine and norepinephrine concentrations. A three-way tap was placed on the catheter to allow rinsing with a syringe containing a mixture of heparin and physiological saline (250 IU.mL $\left.{ }^{-1}\right)$ and blood sampling with a dry syringe after the catheter had been clear of saline. Approximately $5 \mathrm{~mL}$ of blood was sampled at rest (TO) and every $10 \mathrm{~min}$ of exercise during $\mathrm{C}-\mathrm{R}$ (at the 10th and 20th min and the end of cycling, and at the 10th min and the end of the subsequent run), and at every change during $\mathrm{X}-\mathrm{CR}$.

Circulating catecholamine analysis. Approximately $3 \mathrm{~mL}$ of blood was placed in a tube (lithium heparin) containing reduced glutathione $\left(1.2 \mathrm{mg} \cdot \mathrm{mL}^{-1}\right)$ to control cathecholamine oxidation, centrifuged $(3000 \mathrm{rpm}$ for 10 $\min$ ) and stored at $-80^{\circ} \mathrm{C}$ for catecholamine analysis. Plasma catecholamine concentrations were determined by high performance liquid chromatography (HPLC). The catecholamines were extracted by selective absorption to aluminum oxide (Chromsystem-HPLC-Kit, Waters Corp., Milford, MA) before the HPLC run. Aluminum oxide was briefly shaken up in extraction buffer $(50 \mu \mathrm{L})$ and $1 \mathrm{~mL}$ of plasma was added with $50 \mu \mathrm{L}$ internal standard solution (600 pg dihydroxybenzylamine DHBA). The aluminum oxide was then washed three times with brief centrifugation between washes. The catecholamines were extracted with $120 \mu \mathrm{L}$ elution buffer with a brief shaking and then centrifuged (final centrifugation) at $2000 \mathrm{rpm}$ for $1 \mathrm{~min}$. Next, 50 $\mu \mathrm{L}$ of sample eluent was injected into the HPLC column (Resolve TM $5 \mu \mathrm{L}$ sherical C18, HPLC column, Waters Corp., Milford, MA) and eluated with mobile phase. The flow rate was $1 \mathrm{~mL} \cdot \mathrm{min}^{-1}$ at 2,000 psi with a potential of $0.60 \mathrm{~V}$. The chromatogram was analyzed by computer integration (Baseline 815, Waters Corp., Milford, MA).

Blood lactate analysis. Approximately $2 \mathrm{~mL}$ of blood was placed in a tube (EDTA), centrifuged (3000 trs. $\mathrm{min}^{-1}$ for $10 \mathrm{~min}$ ) and stored at $-18^{\circ} \mathrm{C}$ for lactate analysis. The measurements were carried out with an enzymatic method 
without deproteinization (MPR 3 Lactate, Boehringer Kit, Boehringer, Manheim).

Statistical analysis. The results are expressed as means \pm SEM. After the verification of a normal distribution (Gaussian graphical distribution), cardiopulmonary data such as $\dot{\mathrm{VO}}_{2}, \dot{\mathrm{V}}_{\mathrm{E}}, \dot{\mathrm{V}}_{\mathrm{E}} / \dot{\mathrm{V} O} \mathrm{O}_{2}, \dot{\mathrm{V}}_{\mathrm{E}} / \dot{\mathrm{V} C \mathrm{CO}_{2}}, \mathrm{R}, \mathrm{V}_{\mathrm{T}}$, f, and HR were compared using a two-way analysis of variance (ANOVA) with repeated measures for C-R versus $X-C R$. Blood samples were compared using the same method. When significant results were obtained, post hoc comparisons were made using the contrast method. Statistical significance was accepted at the $P<0.05$ level.

\section{RESULTS}

Intensity. $30 \mathrm{~min}$ Cycling and $20 \mathrm{~min}$ running were performed at $68.9 \pm 3.1 \% \dot{\mathrm{VO}}_{2 \max }$ and $65.4 \pm 2.3 \%$ V $\mathrm{O}_{2 \max }$ in $\mathrm{C}-\mathrm{R}$ and at $71.3 \pm 3.3 \% \mathrm{VO}_{2 \max }$ and $64.7 \pm 1.9 \%$ $\mathrm{VO}_{2 \max }$ in X-CR. The distances were identical during cycling (18.9 $\pm 1.4 \mathrm{~km}$ and $18.9 \pm 1.4 \mathrm{~km}$ in C-R and X-CR, respectively) and running (5897 $\pm 381 \mathrm{~m}$ and $5895 \pm$ $337 \mathrm{~m}$ and in C-R and X-CR, respectively).

Physiological parameters. When averaged over the 50 min, $\dot{\mathrm{V}}_{\mathrm{E}} / \dot{\mathrm{VCO}}_{2}$ and $\mathrm{HR}$ were the only parameters that were significantly higher in $\mathrm{X}-\mathrm{CR}$ in comparison with $\mathrm{C}-\mathrm{R}$ (Fig. 1). However, the ventilatory responses (i.e., $\dot{V}_{E}$ and $\left.\dot{\mathrm{V}}_{\mathrm{E}} / \mathrm{VCO}_{2}\right)$ and $\mathrm{HR}$ were significantly higher during the cycling of X-CR than during the cycling of C-R, and $\dot{V}_{E}$ ' $\mathrm{VCO}_{2}$ was significantly higher during the running of $\mathrm{X}-\mathrm{CR}$ than during the running of C-R. (Table 2).

Blood sampling. The time course of the lactate concentration was similar in both X-CR and C-R, except in T1 where lactate concentration was higher in $\mathrm{X}-\mathrm{CR}(P<0.05)$. However, overall lactate concentration tended to be higher in X-CR $(P<0.055)$ (Fig. 2).

The epinephrine concentration was greater $(P<0.025)$ in $\mathrm{X}-\mathrm{CR}$ than C-R $(P<0.025)$, and especially in the first (T1, T2, T3) cycle-run successions (Fig. 3).

The norepinephrine concentration was similar in both trials, except in the first cycle-run succession (T1) of X-CR (Fig. 3).
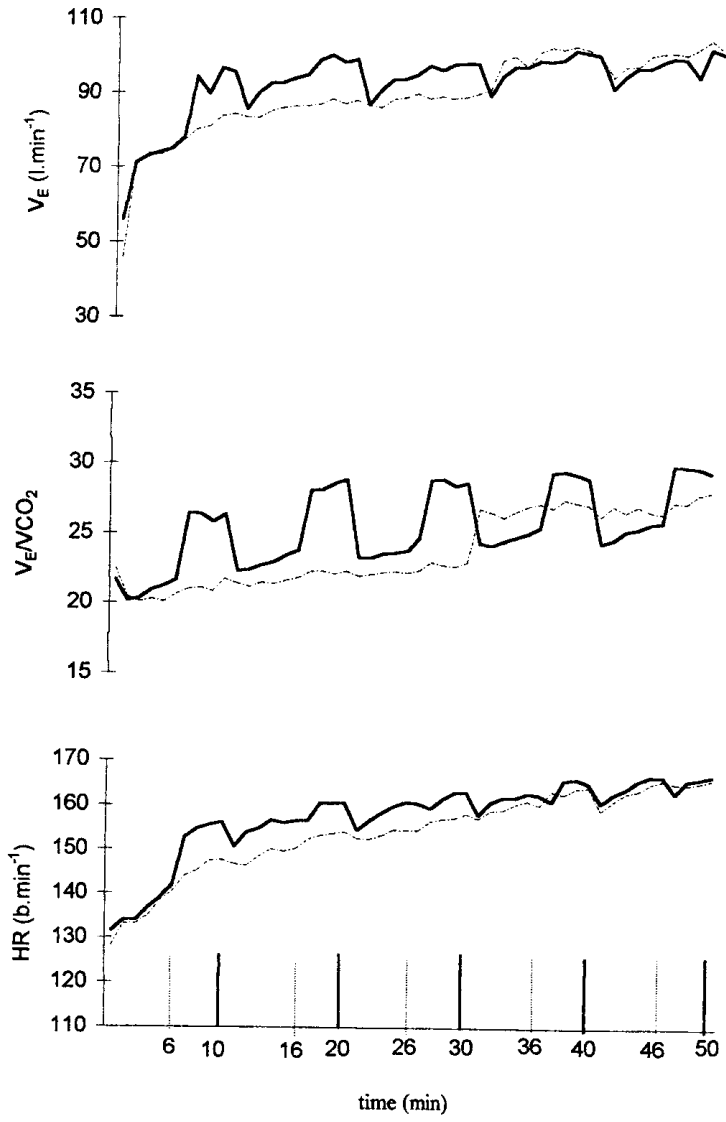

Figure 1-Mean time course for min ventilation $\left(\dot{V}_{E}\right)$, respiratory equivalents for $\mathrm{CO}_{2}\left(\dot{\mathrm{V}}_{\mathrm{E}} / \mathrm{VCO}_{2}\right)$ and heart rate (HR) during the $\mathrm{C}-\mathrm{R}$ (dotted line, 0-30 min: cycling, 30-50 min: running) and the $\mathrm{X}-\mathrm{CR}$ (solid line, $5 \times$ [0-6 min: cycling, 6-10 min: running]) for 13 subjects.

The norepinephrine/epinephrine ratio was significantly lower $(P<0.014)$ in X-CR. However, the timecourse of the two ratios were similar (Fig. 3 ). TABLE 2. Metabolic and cardiopulmonary values measured during the multi-block exercise $(X-C R)$, the cycle-run succession $(C-R)$, the $c y c i e$ of $X-C R$ and $C-R$, and the run of
$X-C R$ and $C-R$; values are means $\pm S E M$.

\begin{tabular}{|c|c|c|c|c|c|c|}
\hline \multirow[b]{2}{*}{ Variables } & \multicolumn{2}{|c|}{$50 \mathrm{~min}$} & \multicolumn{2}{|c|}{ 30-min Cycle } & \multicolumn{2}{|c|}{ 20-min Run } \\
\hline & $\mathrm{X} \cdot \mathrm{CR}$ & C.R & X-CR & $C \cdot R$ & X-CR & C-R \\
\hline \multirow[t]{2}{*}{$\dot{\mathrm{V}} \mathrm{O}_{2}\left(\mathrm{~mL} \cdot \mathrm{kg}^{-1} \cdot \mathrm{min}^{-1}\right)$} & 46.2 & $\begin{array}{r}45.8 \\
1.6\end{array}$ & 47.9 & 46.3 & 44.5 & 45.0 \\
\hline & $\begin{array}{r}1.9 \\
94.2\end{array}$ & $\begin{array}{r}1.6 \\
90.1\end{array}$ & $\begin{array}{c}2.1 \\
92.0^{*}\end{array}$ & 2.1 & 1.3 & 1.6 \\
\hline$\dot{V}_{E}\left(L \cdot \min ^{-1}\right)$ & $\begin{array}{r}94.2 \\
6.0\end{array}$ & $\begin{array}{r}90.1 \\
5.7\end{array}$ & $\begin{array}{c}92.0^{*} \\
6.6\end{array}$ & $\begin{array}{r}83.2 \\
5.2\end{array}$ & 99.7 & 100.4 \\
\hline \multirow{2}{*}{$\dot{\mathrm{V}}_{\mathrm{E}} \mathrm{NO}_{2}$} & 23.9 & $\begin{array}{r}5.7 \\
22.8\end{array}$ & $\begin{array}{r}6.6 \\
22.2\end{array}$ & $\begin{array}{r}5.2 \\
20.9\end{array}$ & 4.4 & 3.9 \\
\hline & 1.4 & 1.7 & $\begin{array}{r}22.2 \\
1.2\end{array}$ & $\begin{array}{r}20.9 \\
0.8\end{array}$ & 26.6 & 25.7 \\
\hline \multirow{2}{*}{$\dot{\mathrm{V}}_{\mathrm{E}} \dot{\mathrm{NCO}}_{2}$} & $25.5^{\star}$ & 23.8 & $\begin{array}{c}1.2 \\
23.1^{*}\end{array}$ & $\begin{array}{r}0.8 \\
21.7\end{array}$ & 1.2 & 1.3 \\
\hline & 1.3 & 1.6 & $\begin{array}{c}23.1^{*} \\
0.9^{*}\end{array}$ & $\begin{array}{r}21.7 \\
0.7\end{array}$ & $28.5^{*}$ & 27.0 \\
\hline \multirow[t]{2}{*}{ R } & 0.94 & 0.95 & $\begin{array}{l}0.9 \\
0.96\end{array}$ & $\begin{array}{l}0.7 \\
0.95\end{array}$ & 1.2 & 1.2 \\
\hline & 0.02 & 0.01 & $\begin{array}{l}0.96 \\
0.02\end{array}$ & 0.95 & 0.93 & 0.94 \\
\hline \multirow[t]{2}{*}{$f\left(c \cdot \min ^{-1}\right)$} & 42.5 & 40.9 & $\begin{array}{l}0.02 \\
37.9\end{array}$ & 0.01 & 0.01 & 0.01 \\
\hline & 3.2 & 3.4 & $\begin{array}{r}3.9 \\
2.4\end{array}$ & $\begin{array}{r}35.5 \\
23\end{array}$ & 50.6 & 50.2 \\
\hline \multirow[t]{2}{*}{$V_{T}(L)$} & 2325 & 2263 & 2494 & $2407^{2.3}$ & 2.8 & 3.3 \\
\hline & 172 & 143 & 193 & $\begin{array}{r}2407 \\
145\end{array}$ & 2063 & 2045 \\
\hline \multirow{2}{*}{$H R\left(b \cdot \min ^{-1}\right)$} & $158^{\star}$ & 154 & $156^{*}$ & 145 & 99 & 112 \\
\hline & 4 & 4 & 5 & $\begin{array}{r}148 \\
4\end{array}$ & 162 & 163 \\
\hline
\end{tabular}




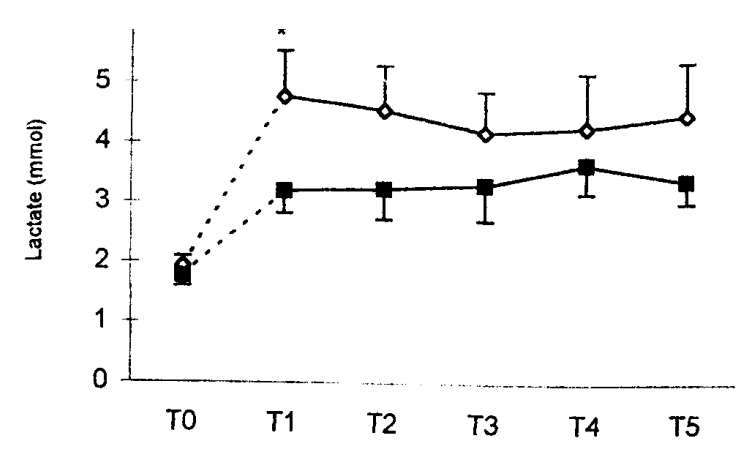

Figure 2-Lactate concentration in response to multi-cycle-run block exercise $(\diamond)$ and to cycle-run exercise $(E) .{ }^{*} P<0.05$. (T1, T2, T3: C-R cycling; T4, T5; C-R running).

\section{DISCUSSION}

The results of this study show that multi-block training, when conducted at the same speed and intensity as a cycleun succession, induces the same physiological responses, especially during the running segments.

The overall circulating lactate tended to rise in X-CR, and the epinephrine response was greater in $X-C R$ compared with $C-R$. These findings suggest that $X-C R$ (i.e., in relation with interval or switching exercises) depended substantially more on glycolytic processes $(5,9,12)$. It could also be related to the use of upper body muscles during running leg xxercise: Hooker et al. (14) demonstrated that at the same absolute $\mathrm{VO}_{2}$ plasma epinephrine was significantly higher during arm than during leg exercise. This greater epinephrine response would also explain the greater HR response obtained during $\mathrm{X}-\mathrm{CR}(8)$.

The greater response of norepinephrine during $X-C R$ only at $\mathrm{T} 1$ may reflect the additional stress induced by the first exercise change (i.e., cycle to run) $(24,25,29)$ and the inreased mental load required to effect this initial change $1,7,28$ ); a mental load not required in $\mathrm{T} 1$ during $\mathrm{C}-\mathrm{R}$. This attentional load did not occur after the first exercise block (T1), as the norepinephrine responses to X-CR were thereafter similar to those of $C-R$, which suggests an adaptation to this specific type of training model.

We used a protocol that did not enable us to employ an arterial catheter. Instead, we obtained the catecholamine level resulting from the production-elimination. We assume that the venous catecholamine level did not reflect the arterial concenuration $(10,13)$ and that the use of an arterial catheter would have been better (3). However, the subjects were compared to themselves and the exercise intensities and durations and thermal conditions were the same in both the C-R and X-CR trials. We may thus also assume that the changes in venous cathecholamines were linked to exercise specificity (21) and not to exercise intensity (9), exercise duration (27) or hyperthermia (26). Moreover, as blood sampling were drawn at the end of ach X-CR within $20 \mathrm{~s}$, which is less than plasma half-life of satecholamine (4). We also may suppose that plasma concenrrations noted during $\mathrm{X}-\mathrm{CR}$ reflected prior $\mathrm{X}$-CR bout exercise and not the $1 \mathrm{~min}$ recovery period.
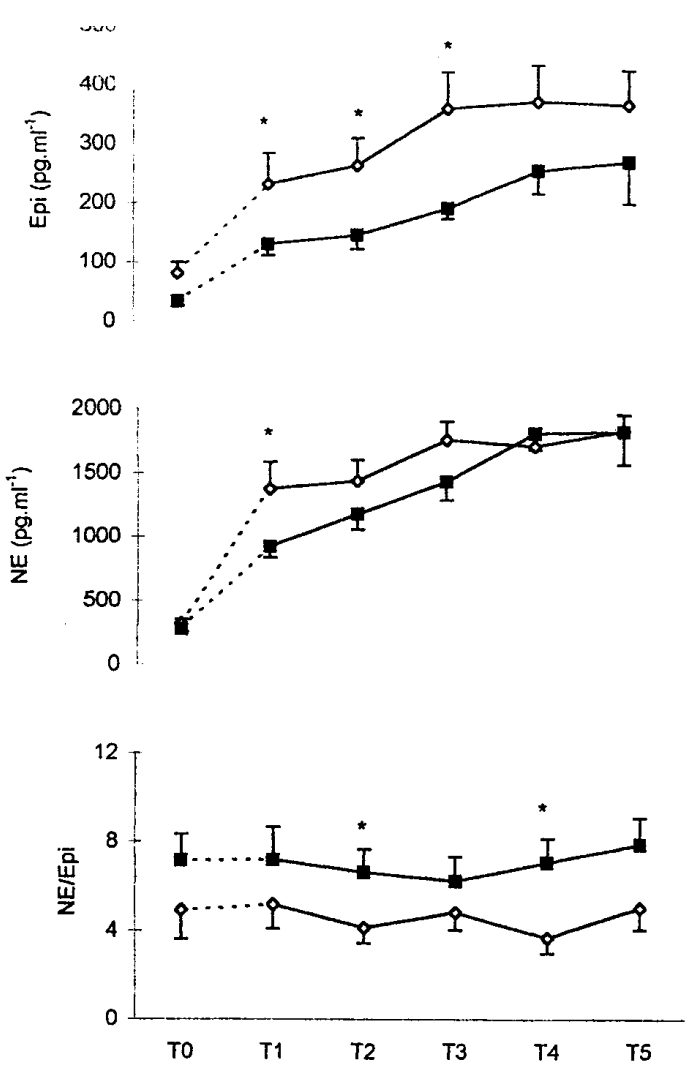

Figure 3-Plasma epinephrine (Epi), norepinephrine (NE) concentration and ratio of $N E / E$ pi in response to multi-cycle-run block exercise (W) and to cycle-run exercise $(\diamond) .{ }^{*} P<0.025$ (T1, T2, T3: C-R cycling; T4, T5: C-R running).

The greater $\dot{\mathrm{V}}_{\mathrm{E}} / \mathrm{VCO}_{2}$ response during the $\mathrm{X}-\mathrm{CR}$ trial in comparison with the $\mathrm{C}-\mathrm{R}$ trial reflects a decrease in ventilatory efficiency during $\mathrm{X}-\mathrm{CR}$, which has to be related to the greater $\dot{V}_{E}$ response during this exercise. This "hyperventilation" cannot be attributed to a ventilatory compensation for metabolic acidosis, because the $\mathrm{VCO}_{2} / \mathrm{VO}_{2}$ ratio was the same in the two exercises. It could be attributed, however, to other factors: 1) To a tendency toward a greater lactate concentration during $\mathrm{X}-\mathrm{CR}$, indeed, Hardarson et al. (11) showed that $\mathrm{La}^{-}$can stimulate $V_{E}$ without any accompanying changes in either arterial $\mathrm{pH}$ or arterial pressure in $\mathrm{CO}_{2}$, which was the case in our study, as no rise in $\mathrm{CO}_{2}$ was noted. 2) It could also be attributed to a greater motor cortex activation due to the alternating cycling-running exercise and interval nature of exercise. Indeed, it has generally been accepted that the stimuli for the exercise hyperventilation are both neural and humoral (19) and neurogenic mechanisms have been suggested as being involved in the differences in the control of exercise ventilation between arm and legs exercises (17). 3) Although we did not measure $\mathrm{K}^{+}$, hyperkalaemia may also have been implicated in this response. $\mathrm{K}^{+}$has been demonstrated as playing an important role as a substance which can stimulate exercise hyperpnoa (30) through it exciting action on CIII and CIV afferents $(20,23)$. To our knowledge, there was no study comparing $\mathrm{K}^{+}$ 
response between continuous versus interval work, however, one could not withdraw the possibility that $\mathrm{K}^{+}$accumulation may have been greater during $X-C R$.

When compared with $\dot{\mathrm{V}}_{\mathrm{E}}$ in C-R cycling, the greater ventilation noted during the cycling in $\mathrm{X}-\mathrm{CR}$ may have been induced by an inertia of the ventilatory system and may be related to a lingering effect from the previous run, which would result in a situation wherein the greater $\dot{V}_{E}$ reached during $\mathrm{X}-\mathrm{CR}$ running would persist during $\mathrm{X}-\mathrm{CR}$ cycling because of the multiplicity of relatively brief blocks.

To sum up, the present study demonstrated that multiblock training is a good method to stimulate the specific adaptations required during the cycle-run succession, and particularly during the cycle-run transition. However, multi-

\section{REFERENCES}

1. ABERCROMBtE, E., and B. JacoBs. Single unit response of noradrenergic neurons in the locus coeruleus of freely moving cats: II Adaptation to chronically presented stressful stimuli. J. Neurosci. 7:2844-2848, 1987.

2. Beaver, W. L., K. Wasserman, and B. J. Whipp. A new method for detecting anaerobic threshold by gas exchange. J. Appl. Physiol. 60:2020-2027, 1986.

3. Best, J. D., and J. B. Halter. Release and clearance rates of epinephrine in man: importance of arterial measurements. J. Clin. Endocrinol. Metab. 55:263-268, 1982.

4. Boone, JR. J. B., T. Sherraden, K. Pierzchala, R. Berger, and G. R. VAN LOON. Plasma met-enkephalin and catecholamine responses to intense exercise in humans. J. Appl. Physiol. 73:388392, 1992.

5. Chritensen, N. J., H. Galbo, J. f. Hansen, B. Hesse, E. A. Richter, and J. Trap-Jensen. Catecholamines and exercise. Diabetes 28:58-62, 1979.

6. De Viro, G., M. Bernardi, E. Sproviero, and F. Figura. Decrease of endurance during Olympic Triathlon. Int. J. Sports Med. 16: 24-28, 1995.

7. Foote, S., F. Bloom. and G. Aston-Jones. Nucleus locus coerulus: new evidence of anatomical and physiological specificity. Physiol. Rev. 63:844-913, 1983.

8. Foster, $\mathrm{C}$. VO $\mathrm{VO}_{2 \max }$ training indices as determinants of competitive running performance. J. Sports Sci. 1:13-22, 1983.

9. Galbo, H., J. J. Holst, and N. J. Christensen. Glucagon and plasma catecholamine responses to graded and prolonged exercise in man. J. Appl. Physiol. 38:70-76, 1975.

10. Halter, J., A. Pflug, and A. Tolas. Arterial-veinous differences in plasma catecholamines in man. Metabolism 29:9-12, 1980.

11. Hardarson, T., J. O. Skarphedinsson, and T. Sveinsson. Importance of the lactate anion in control of breathing. J. Appl. Physiol. $84: 411-416,1998$.

12. Hartley, L. H., J. W. Mason, R. P. Hogan, et al. Multiple hormonal responses to prolonged exercise in relation to physical training. J. Appl. Physiol. 33:607-610, 1972.

13. Huemdahl, P., U. Freyschuss, A. Juhlin-Dannfelt, and B. Linde. Plasma catecholamines and mental stress. In: The Sympathadrenal System: Physiology and Pathophysiology: N. Christensen, O. Henriksen, and N. Lassen (Eds.). New York: Raven Press. 1986. pp. 237-249.

14. Hooker, S. P.. C. L. Wells, M. M. Manore, S. A. Philip, and N. MarTin. Differences in epinephrine and substrate responses between arm and leg exercise. Med. Sci. Sports Exerc. 1990.

15. Hue, O., D. le Gallais, D. Chollet, A. Boussana, and C. PreFAUT. The influence of prior cycling on biomechanical and cardiorespiratory response profiles during running in triathletes. Eur. J. Appl. Physiol. 77:98-105. 1998. block training seems to induce a greater catecholaminergic response than the cycle-run succession. This greater response may be an inherent effect of multi-block training, or it may have been due to the triathletes' lack of experience with this training model. Obviously, it may also have been due to a combination of a lack of experience and an inherent effect. In any case, the efficacy of the multi-block model needs to be more thoroughly evaluated over the course of a longer-term training program.

Address for correspondence: O. Hue, UFR-STAPS Antilles-Guyane, Campus de Fouillole, BP 592, 97159 Pointe à Pitre Cedex; E-mail: HueO@wanadoo.fr.

16. Hue, O., D. Le Gallais, D. Chollet, A. Boussana, and C. PreFAUT. Ventilatory responses during experimental cycle-run transition in triathletes. Med. Sci. Sports Exerc. 31:1422-1428, 1999.

17. Ishida, K., T. TAKAISHI, and M. Mryamura. Ventilatory responses at the onset of passive movement and voluntary exercise with arms and legs. Acta. Physiol. Scand. 151:343-352, 1994.

18. Kreider, R. B., T. Boone, W. R. Thompson, S. Burke, and C. W. CORTES. Cardiovascular and thermal responses of triathlon performance. Med. Sci. Sports Exerc. 20:385-390, 1988.

19. Lewis, S. F., W. F. Taylor, R. M. Graham, W. A. Pettinger, J. E Schutte, and C. G. BlomQvist. Cardiovascular responses to exercise as functions of absolute and relative workload. J. Appl. Physiol. 54:1341-1323, 1983.

20. Lindinger, M. I., and G. SJogaARd. Potassium regulation during exercise and recovery. Sports Med. 11:382-401, 1991.

21. Mazzeo, R. S. Catecholamine responses to acute and chronic exercise. Med. Sci. Sports Exerc. 23:839-845, 1991.

22. O'Toole, M. L., and P. S. Douglas. Applied physiology of a triathlon. Sports Med. 8:201-225, 1989.

23. Paterson, D. J. Potassium and breathing exercise. Sports Med. 23:149-163, 1997.

24. Savard, G. S., S. Strange, B. Kiens, E. A. Richter, N. J. ChrisTIANSEN, and B. SALTin. Noradrenaline spillover during exercise in active versus resting skeletal muscle in man. Acta Physiol. Scand. 131:507-515, 1987.

25. SEals, D. R., R. G. VICtor, and A. L. MARK. Plasma norepinephrine and muscle sympathetic discharge during rhythmic exercise in humans. J. Appl. Physiol. 65:940-944, 1988.

26. Shum, A., G. F. Johnson, and K. V. Flattery. Influence of ambient temperature on excretion of catecholamines and metabolites. Am. J. Physiol. 216:1164-1169, 1969.

27. Sothmann, M., A. Gustafson, and M. Chandler. Plasma free and sulfoconjugated catecholamine responses to varying exercise intensity. J. Appl. Physiol. 63:654-658, 1987.

28. Sothmann, M. A., B. Hart, T. Horn, and A. Gustafson. Plasma catecholamine and performance associations during psychological stress: evidence for peripheral noradrenergic involvement with an attention demanding task. Hum. Perform. 1:31-43, 1988.

29. Wallin, B. G., G. Sundorf, B. Eriksson, P. Dominiak, H. Gro BECKER, and L. F. LindBLAD. Plasma noradrenaline correlates to sympathetic muscle nerve activity in normotensive man. Acto Physiol. Scand. 111:69-73, 1981.

30. Yoshida, T., M. Chida, M. Ichioka, K. Makiquchi, J. Equchi, and $M$. UDO. Relationship between ventilation and arterial potassium concentration during incremental exercise and recovery. Eus: J. Appl. Physiol. 61:193-196, 1990. 